\title{
Akılcı ve Sezgisel Karar Verme Stilleri Ölçeğinin Türkçeye Uyarlanması
}

\author{
DOI: 10.26466/opus.720827 \\ *

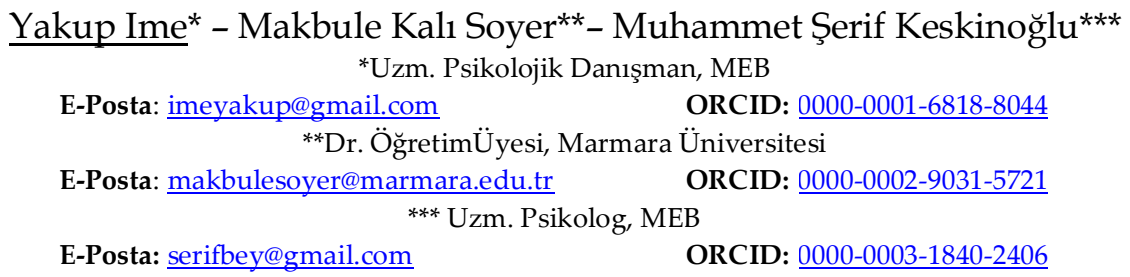

Öz

Bu araştırmada rasyonel ve sezgisel karar verme biçimleri ölçeğini Türkçe'ye uyarlayıp, güvenilirliğini ve geçerliliğini incelemek amaçlanmıştır. Veriler, 357 kadın ve 383 erkek olmak üzere toplam 740 üniversite öğrencisi grubundan toplanmıştır. Doğrulayıcı faktör analizi ile ölçeğin psikometrik özellikleri Mplus Programinda incelenmiştir. Akılcı ve sezgisel karar verme ölçeği ile karar verme stilleri ölçeği arasındaki ilişki ölçüt geçerliliği kapsamında incelenmiştir. Ölçeğin ölçüt ile ilgili geçerliliği, iç tutarlılı̆̆ı ve test-tekrar test güvenirliği SPSS programında hesaplanmıştır. Doğrulayıcı faktör analizi sonuçları, akılcı ve sezgisel karar stilleri ölçeğinin iki faktörlü yapısının doğrulandığın göstermiştir. Ölçüt geçerlik kapsaminda rasyonel ve sezgisel karar biçimleri ölçeği ile karar verme biçimleri alt ölçekleri arasında pozitif korelasyonlar bulunmuştur. Toplam ölçek için Cronbach'ın alfa değeri .80 'dir. Alt ölçek boyutları için, akılcı karar verme için 0,90 ve sezgisel karar verme için 0,85 olduğu görülmüştür.Ölçeğin bütünü için test-tekrar test korelasyon değeri .86 şeklinde bulunmuştur. Araştırma bulguları, akllcı ve sezgisel karar verme ölçeğinin Türkiye'deki üniversite öğrencileri ile psikometrik uyumluluğa sahip olduğunu ve yapılacak bilimsel çalışmalarda kullanılabileceğini göstermiştir.

Anahtar Kelimeler: karar verme, akılcı, sezgisel, ölçek uyarlama 


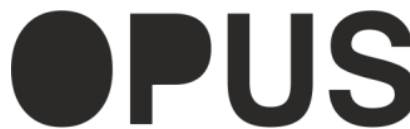

Uluslararası Toplum Araştırmaları Dergisi International Journal of Society Researches
E-ISSN : 2528-9535

YIl Year: 10

Cilt Volume: 16

Sayı Issue :Eğitim ve Toplum Özel Sayısı

Aralık December 2020

Makalenin Geliş Tarihi Received Date: 15/04/2020

Makalenin Kabul Tarihi Accepted Date: 29/12/2020

\title{
Adaptation of Rational and Intuitive Decision Making Styles Scale to Turkish
}

\begin{abstract}
This research was designed to adapt the rational and intuitive decision styles scale into Turkish and to evaluate its reliability and validity. Research sample of the research consisting of 740 university students. Participants are 357 women and 383 men. CFA was used to test the psychometric properties of the scale in the Mplus Program. The relationship between rational and intuitive decisionmaking scale and decision-making styles scale was examined within the context of criterion validity. The criterion validity, internal coherency and test-retest reliability was calculated in the SPSS program. According to results, structure of the the rational and intuitive decision styles has been validated. For the criterion validity, positive correlations were found between the rational and intuitive decision styles scale and decision-making styles subscales. Cronbach's alpha was .80 for the total scale. For subscales dimensions, it was found to be .90 for rational decision making and .85 for intuitive decision making. The test-retest correlation coefficient was .86. This research showed that rational and intuitive decision-making scale has great psychometric compatibility with university students in Turkey, and it could be used in studies with university students.
\end{abstract}

Keywords: decision making, rational, intuitive, scale adaptation 


\section{Giriş}

Hayat sayısız kararları içerir ancak bireyin karar vermesi basit bir süreç değildir. Zaman zaman bireyler kararın hatalı bir mantığa dayandığını bilse bile uygun olmayan bir seçim yapmak zorunda kalabilir. Esasen bu durum birçok bireyin karar verirken farklı zihinsel süreçleri kullanmasından kaynaklanabilir. Nitekim Philips, Fletcher, Marks ve Hine (2016) bu durumu ikili süreç biliş kuramı temelinde, iki farklı bilgi işleme türüne bağlamaktadır. Birincisi otomatik ve hızlı işleyen, çalışan hafızayı kullanmayı gerektirmeyen sezgisel işlem sürecidir. İkincisi ise nispeten daha yavaş, çaba gerektiren, analitik, kural tabanlı ve çalışma belleği gerektiren analitik ve akılcı işlem sürecidir. Bu bilgilerden de anlaşılacağ 1 üzere karar verme, bilgi toplama ve işleme, problem çözme, yargılama, hafıza ve öğrenme gibi birçok bilişsel süreci içerir.

Karar verme, bir kişinin amacına ulaşma aşamasındayken farklı alternatifler arasında seçim yapma süreci olarak tanımlanmaktadır (Miller ve Byernes,2001). Bireyler karar verirken farklı karar verme stillerini kullanırlar. Bu farklı karar verme stilleri sayesinde, bir kişinin görünüşte aynı durumlarla karşılaşırken neden bu kadar farklı karar süreçlerini kullandığını anlayabiliriz (Nutt,1990).Karar verme biçimlerinin kişiden kişiye değişiklik gösterdiği, bazı bireylerin uzun düşünceler sonucu, bazılarının ise daha hızlı izlenimlerine göre karar aldıkları belirtilmektedir. Uzun düşünceler sonucu karar alan bireyler karar vermeye bilişsel ve sistematik yaklaşırken, sezgisel karar alan bireyler daha duygusal ve sistematik olmayan bir yaklaşım benimsemektedir. Araştırmacılar karar vermenin bireyin kişilik özelliklerine, görev ve çevresel faktörlere göre değiştiğini ifade etmektedir (Hunt, Krzystofiak, Meindl ve Yousry, 1989).

Karar verme stillerinin çeşitleri hakkında çeşitli öneriler sunulmaktadır. Literatürde çokça kullanılan Harren modeline göre üç farklı karar verme stili vardır. Bunlar rasyonel (rasyonalite kullanarak karar verme), bağımlı (başkalarının görüşü ile karar verme) ve sezgisel (duygu ve duygulara dayalı kararlar almak) karar verme stilleridir (Baiocco, Laghi ve D'Alessio, 2009).Diğer yandan, Scott ve Bruce (1995) dört farklı karar verme stilinin olduğunu belirtmektedir. Birincisi bireyin karar verirken tüm alternatifleri dikkatlice değerlendirdiği rasyonel karar verme stili, ikincisi his ve sezgilere dayanan sezgisel karar verme, üçüncüsü bireyin diğerlerinin öneri ve öğüt- 
lerine açık şekilde olduğu bağımlı karar verme, sonuncusu ise karar vermekten kaçınan kaçınan karar verme stilidir. Bu doğrultuda karar verme stilleri ile ilgili çalışmalar incelendiğinde genel olarak sezgisel, deneyimsel, mantıklı, akılcı, analitik, kaçınan ve erteleyen gibi karar verme stillerinin birçok çalışmada ortak olduğu görülmektedir.

Bireyler zaman zaman karar verme stilleri kullaniyor olsalar da genel olarak baskın bir karar verme stiline sahiptirler (Driver,Brousseau ve Hunsaker, 1990). Bireylerin kullanmış olduğu karar verme stilleri insan zihninin karar verirken nasıl işlediğini anlamak için bir araçtır (Rowe ve Davis, 1996). Rowe ve Mason (1987) bu durumu karar verme stilleri bireyin karar aşamasındaki bilgiyi kullanma biçimidir şeklinde ifade etmektedir. Bireyin karar verme süreçlerinde bilgiyi kullanma biçimlerinin farklı olabileceği sonucundan hareketle karar verme stillerinin kavramlaştırılması ile çeşitli çalışmalar yapılmaktadır (Kinicki ve Williams, 2013). Ancak, tüm yapılan çalışmalara rağmen evrensel olarak karar verme stilleri çeşitliliği konusunda fikir birliğine varılmamıştır. Buna bağlı olarak da karar verme biçimlerini ölçmeye yönelik çeşitli ölçüm araçları geliştirilmiştir (Leykin ve DeRubeis, 2010).

Gerçekte, karar stilleri etkili karar vermenin belkemiğini oluşturur (Rowe ve Boulgarides, 1992). Bu bağlamda karar verme stilleri giderek artan ilgiyle beraber dünya ve Türkiye üzerinde birçok araştırmacının ilgisini çekmektedir (Wood ve Highhouse, 2014; Taşdelen, 2001). Artan bu ilgiye rağmen birçok araştırmacı tarafından karar verme stillerinin psikometrik olarak incelemesini sağlayan ölçekler gerek yeterli teorik altyapıya dayanmaması gerekse yapı geçerliliklerinin yetersizlikleri nedeniyle eleştirilmektedir (Mohammed ve Schwall, 2009; Spicer ve Sadler-Smith, 2005). Bu eleştirilerden hareketle Hamilton, Shih ve Mohammed (2016) karar verme stilleri üzerine daha sistematik ve eleştirileri de göz önünde bulundurarak yeni bir ölçüm aracı geliştirmişlerdir. Bu ölçüm aracı karar verme stillerini akılcı ve sezgisel olarak ele almaktadır.Akılı karar verme stili, kapsamlı bir araştırma, tüm seçeneklerin ve muhtemel alternatiflerin sistematik olarak değerlendirilmesidir. Diğer taraftan sezgisel karar verme stili ise öncelikle önsezilere ve duygulara dayanan hızlı bir karar verme sürecinin kullanılmasını ifade eder (Scott ve Bruce, 1995).Türkiye'de ise alan yazın incelendiğinde karar verme stillerini ölçmeye yönelik olarak çeşitli ölçeklerin var olduğu görülmektedir (Çolakkadıŏlu, 2012; Taşdelen, 2001). Ancak Hamilton ve diğ. (2016) tara- 
fından karar verme stilleri ile ilgili olarak kapsamlı bir incelemenin ardından akılcı ve sezgisel karar verme temel ikili bilgi işleme sistemine uygun olarak, gerek psikometrik özellikleri açısından iyi uyum değerlerine sahip gerekse kısa ve uygulanabilir bir ölçüm aracı geliştirmişlerdir. Dolayısıyla geliştirilen ölçüm aracı hem uygulanabilirlik açısından kolay hem de psikometrik açından iyi uyum değerlerine sahiptir. Dolayısıyla karar verme stilleri alanındaki ölçme araçlarına zenginlik kazandırması açısından güncel bir ölçeğin literatüre kazandırılmasının bu alandaki bilimsel çalışmalara katkı sağlayacağı düşünülmektedir. Dolayısıyla bu çalışmada Hamilton ve diğ. (2016) tarafından geliştirilen akılcı ve sezgisel karar verme ölçeğinin Türkçeye uyarlanması amaçlanmıştır.

\section{Yöntem}

\section{Araştırma Modeli}

Bu çalışmada rasyonel ve sezgisel karar verme ölçeğini Türkçeye uyarlayıp, güvenilirliğini ve geçerliliğini incelemek hedeflenmiştir. Bu bağlamda tarama yöntemi kullanılmıştır. Tarama yöntemi, belirli bir örneklemden anketler vasıtasıyla bilgi toplamak amacıyla yapılan nicel bir araştırma yöntemidir (Lavrakas, 2008).

\section{Evren ve Örneklem}

Bu araştırmaya dört farklı gruptan toplam 740 üniversite öğrencisi katılmıştır. Araştırmaya ilk olarak dil geçerliği çalışması için 2019-2020 akademik yılı güz döneminde İngilizce ve Türkçeye iyi derecede hakim üniversiteye devam etmekte olan 26 kadın, 20 erkek olmak üzere toplam 46 üniversite öğrencisi katılmıştır (\%56.5 kadın,\% 43.5 Erkek, yaş $\bar{X}=21.08$, Ss=1.20) . DFA ve güvenirlik çalışması için yine aynı akademik yıl içerisinde öğrenim görmekte olan 197 kadın ve 222 erkekten oluşan toplam 419 üniversite öğrencisi katılım göstermiştir ( $\% 47.8$ kadın, \% 52.2 Erkek, $\bar{X}=21.21$ yaş $\mathrm{Ss}=3.99$ ). Ölçüt bağlantı geçerlik çalışması için araştırmaya yine aynı akademik dönem içerisinde 99 kadın ve 118 erkekten oluşan toplam 217 üniversite öğrencisi katılım göstermiştir (\%45.6 kadın, \% 54.4 Erkek, $\bar{X}=20.94$ yaşSs=3.74).Test tekrar-test güvenirlik çalışması için ise yine aynı akademik 
dönem içerisinde 35 kadın 23 erkek toplam 58 üniversite öğrencisi katılmış$\operatorname{tır}(\% 60.3 \mathrm{kız}, \% 39.7$ Erkek, $\bar{X}=21.10$ yaş $\mathrm{Ss}=1.20)$.

\section{Veri Toplama Araçlan}

Akılcı ve Sezgisel Karar Verme Ölçeği: Ölçek Hamilton ve dĭ̆. (2018) tarafından geliştirilmiştir. Ölçeğin ilk geliştirme aşamasında oluşturulan 24 madde, hesaplanan psikometrik ölçümler sonucunda 10 maddelik, iki alt boyutlu bir yapı elde edilmiştir. Ölçeğin ilk alt boyutu olan akılcı karar verme ilk beş maddeden, sezgisel karar verme ise sonraki beş maddeden oluşmaktadır. Ölçek 5'li likert yapıdan oluşmaktadır. Ölçeğin Türkçeye uyarlanması orijinal halinde olduğu gibi üniversite öğrencileri örnekleminden gerçekleştirilmiştir. Uyarlama çalışmasına toplamda 740 üniversite öğrencisi katılmıştır. Yapı geçerliğini belirlemek amacıyla DFA yapılmış ve orjinal yapıdaki alt boyutlarını oluşturan ikili yapının doğrulandığı görülmüştür. İki boyut ile temsil edilen modelin uyum değerlerinin kabul edilebilir değerler olduğu bulunmuştur $\left(\mathrm{x}^{2} / \mathrm{df}=2.57, \mathrm{CFI}=.98, \mathrm{TLI}=.97\right.$, SRMR=.06, RMSEA=.06). Ölçüt bağlantı geçerlik çalışması sonucu akılcı ve sezgisel karar verme ölçeği ile karar verme stilleri ölçeği alt ölçekleri arasında pozitif yönde anlamlı ilişkilerin varlı̆̆ı bulunmuştur. Cronbachalpha değeri ölçeğin bütünü için .80 , alt ölçekler olan akılcı karar verme için .90, sezgisel karar verme için .85 olarak hesaplanmıştır. Test-tekrar test korelasyon katsayısı ise. 86 olarak hesaplanmıştır.

Karar Verme Stilleri Ölçeği:Akılcı ve sezgisel karar verme stilleri ölçeğinin Türkçe'ye uyarlanması aşamasında ölçüt geçerliği çalışması için Karar Verme Stilleri Ölçeği kullanmıştır. Scott ve Bruce (1995) tarafından geliştirilen ölçek Taşdelen (2001) vasıtasıyla Türkçeye uyarlanmıştır. Ölçek, rasyonel, sezgisel, bağımlı, kendiliğinden anlık ve kaçıngan karar verme stilleri olmak üzere beş alt ölçek ve 25 maddeden meydana gelmektedir. Ölçeğin Türkçe uyarlaması için yapılan çalışmada orijinal halindeki beş alt boyut doğrulanmıştır. Güvenirlik çalışmasında ise ölçeğin alt boyutları için cronbach alpha katsayısı .76 ile .79 arasında değişlik gösterdiği, tümü için ise .74 olarak belirtilmektedir (Taşdelen, 2001). 


\section{Ölçeğin Türkçe Uyarlanması Kapsamında Yapılan İşlemler}

Akılcı ve sezgisel karar verme stilleri ölçeğinin Türkçeye uyarlama çalışması için öncelikle ölçeğin orijinal hali İngilizce ve Türkçe dillerine hakim 6 uzman tarafından Türkçeye çevrilmiştir. Bu noktada çeviri uzmanlarından gelen çevirilerin farklılık gösterdiği noktalar, anlam ve kültüre uygunluk açısından göz önünde bulundurulmuştur (Şeker ve Gençdoğan, 2014). Elde edilen Türkçe form 5 uzman tarafından tekrar İngilizceye tercüme edilmiştir. Daha sonra orijinal ilk form ile elde edilen ikinci form arasındaki tutarlılık incelenmiştir. Elde edilen yeni ölçeğin anlam ve dilbilgisi yönünden orijinal ölçekten farklı olmadığı görülmüştür.

Katılımclara bilgilendirilmiş onam yapıldıktan sonra veri toplama araçları yüz yüze uygulanmıştır. Verilerin analizi için, dil geçerliği, ölçüt bağlantı geçerliği, iç tutarlık güvenirliği, test tekrar test ve doğrulayıcı faktör analizi yöntemleri yapılmıştır. Ölçek uyarlama araştırmaları için orijinal araştırmadaki ölçeğin hedeflenen kültüre psikometrik açıdan uygun olup olmad1ğını belirlemek amacıyla DFA yönteminin kullanılması belirtilmektedir (Sireci, Patsula, Hambleton, 2005). Bu nedenle bu çalışmada da doğrulayıcı faktör analizi yöntemi tercih edilmiştir. Gizil değişkenler ile kuramların test edilmesi amacıyla üst düzey araştırmalarda doğrulayıcı faktör analizi yöntemi kullanılır (Tabachnick ve Fidell, 2001). Doğrulayıcı faktör analizinde daha önceden belirlenen bir kuramsal yapı doğrultusunda geliştirilen ölçme aracına dayanarak, hedef yapının doğrulanıp doğrulanmadığı değerlendirilir (Maruyama, 1998). Elde edilen verilerin analizlerinden önce verilerin eksik olup olmadığı ve normal dağılıp dağılmadığı test edilmiştir. Verilerin tam olduğu ve normal dağılım gösterdiği görülmüştür. DFA hesaplamları için M.Plus programının 6.1 versiyonu kullanılmıştır.

\section{Bulgular}

\section{Dil geçerliği}

İngilizce ve Türkçe dilleri iyi derecede olan 46 üniversite öğrencisine ölçeğin orjinal formları ile yedi gün arayla uygulanan Türkçe form toplam puanları arasındaki korelasyon değerleri Tablo 1'de, ölçek maddelerinin korelasyon değerleri Tablo 2'de ve ilişkili grup t-testi bulguları ise Tablo 3'te verilmektedir. 
Tablo 1. Orijinal form ile Türkçe form arasındaki ilişkiyi gösteren pearson korelasyon bulgular

\begin{tabular}{lllll}
\hline & $N$ & $\bar{X}$ & $S s$ & $R$ \\
\hline Türkçe form & 46 & 34.19 & 4.40 & $.90^{* *}$ \\
İngilizce form & 46 & 34.26 & 4.21 & \\
\hline
\end{tabular}

${ }^{* *} \mathrm{p}<.01$

Tablo 1'den de anlaşıldı̆̆ arasındaki korelasyon değeri $r=.90(p<.01)$ şeklinde elde edilmiştir. Ölçeğin alt boyutarına ilişkin ise: akılcı karar verme alt boyutu için $r=.88$, sezgisel karar verme alt boyutu için $r=.94$ olarak bulunmuştur. $\mathrm{Bu}$ analiz bulgularına dayanarak ölçeğin Türkçe formunun, orjinal formuna denk olduğu ifade edilebilir.

Tablo. 2. Türkçe ve Ingilizce formlar arasındaki ilişkiye yönelik pearson momentler çarpımı korelasyon değerleri

\begin{tabular}{llll}
\hline & $\mathrm{N}$ & $\mathrm{r}$ & $\mathrm{p}$ \\
\hline Tr 01 \& İng 01 & 46 & .72 & .001 \\
Tr 02 \& İng 02 & 46 & .87 & .001 \\
Tr 03 \& İng 03 & 46 & .75 & .001 \\
Tr 04 \& İng 04 & 46 & .83 & .001 \\
Tr 05 \& İng 05 & 46 & .59 & .001 \\
Tr 06 \& İng 06 & 46 & .86 & .001 \\
Tr 07 \& İng 07 & 46 & .92 & .001 \\
Tr 08 \& İng 08 & 46 & .89 & .001 \\
Tr 09 \& İng 09 & 46 & .76 & .001 \\
Tr 10 \& İng 10 & 46 & .70 & .001 \\
\hline
\end{tabular}

Tablo 2'den de anlaşıldığg gibi maddelerin bütünü için İngilizce ve Türkçe formları arasındaki korelasyon değerlerinin yüksek düzeyde ve anlamlı olduğu görülmektedir.

Tablo 3.Dil geçerlik için ilişkili grup t-testi bulgular

\begin{tabular}{|c|c|c|c|c|c|}
\hline & & $\overline{\mathrm{X}}$ & Ss & $t$ & $\mathrm{p}$ \\
\hline \multirow[t]{2}{*}{1} & $\operatorname{Tr} 1$ & 4.23 & .79 & 1.55 & .12 \\
\hline & İng1 & 4.08 & .96 & & \\
\hline \multirow[t]{2}{*}{2} & $\operatorname{Tr} 2$ & 4.04 & .66 & 1.35 & .18 \\
\hline & İng 2 & 3.97 & .64 & & \\
\hline \multirow[t]{2}{*}{3} & $\operatorname{Tr} 3$ & 4.26 & .53 & .70 & .48 \\
\hline & İng 3 & 4.21 & .62 & & \\
\hline \multirow[t]{2}{*}{4} & $\operatorname{Tr} 4$ & 3.65 & .79 & -.62 & .53 \\
\hline & İng 4 & 3.69 & .83 & & \\
\hline \multirow[t]{2}{*}{5} & $\operatorname{Tr} 5$ & 2.76 & .87 & -.38 & .69 \\
\hline & İng 5 & 2.80 & .80 & & \\
\hline \multirow[t]{2}{*}{6} & $\operatorname{Tr} 6$ & 3.21 & 1.0 & -.82 & .41 \\
\hline & İng 6 & 3.28 & .91 & & \\
\hline
\end{tabular}




\begin{tabular}{llllll}
\hline 7 & $\operatorname{Tr} 7$ & 2.97 & .93 & -1.13 & .26 \\
\hline & İng 7 & 3.04 & .98 & & .25 \\
\hline 8 & $\operatorname{Tr} 8$ & 2.93 & 1.1 & -1.15 & .47 \\
\hline & $\operatorname{İn} 8$ & 3.02 & .90 & & .72 \\
\hline & $\operatorname{Tr} 9$ & 3.34 & .89 & & .37 \\
\hline 10 & $\operatorname{İn} 9$ & 3.28 & .88 & -.89 & \\
\hline & $\operatorname{Tr} 10$ & 2.76 & .87 & & \\
\hline
\end{tabular}

Tablo 3'te görüldüğü üzere akılcı ve sezgisel karar verme ölçeğinin Türkçe formunun, İngilizce formuna denk olduğu, elde edilen ilişkili grup ttesti bulgularının gösterdiği üzere aralarında anlamlı bir farklılık bulunmadığı hesaplanmıştır (p>.05). Bu bağlamda ölçeğin tüm maddelerinin dil eşdeğerliğene sahip olduğu ifade edilebilir. Tüm bu sonuçlar ışığında ölçeğin Türkçe formunun orijinal formu ile denk olduğu sonucu elde edilmiştir.

\section{Yapı Geçerliği}

Akılcı ve Sezgisel Karar Verme Ölçeği'nin Türkiye'deki üniversite öğrencilerinden oluşan örneklemde doğrulanıp doğrulanmadığını belirlemek için DFA yöntemi analizleri hesaplanmıştır. Buna göre DFA sonucu birincil olarak Ki kare değerinin serbestlik derecesine bölünmesiyle değerlendirilmiştir. Elde edilen oranın beşten küçük olması gerekmektedir (Kline, 2005). Mevcut araştırmada bu değerin (74.59/29) 2,57 olduğu görülmüştür. Tabachnick ve Fidell (2001) tarafından modelin uyum iyiliği değerlerinin CFI, GFI,TLI ve IFI için uyum indekslerinin 90 ve üzerinde, RMSEA ve SRMR için de .08 veya daha küçük olması gerekliliği ifade edilmektedir. Bu doğrultuda elde edilen modelin iyi uyum değerlerine sahip olduğu hesaplanmıştır. Ölçeğe yönelik uyum değerleri Tablo 4'te, maddelere ait faktör yükleri ise Şekil-1'de verilmektedir.

Tablo 4. Akılcı ve Sezgisel Karar verme ölçeğinin uyum iyiliğine yönelik değerleri

\begin{tabular}{lllllll}
\hline Model & $x 2$ & $d f$ & TLI & RMSEA & SRMR & CFI \\
\hline Türkçe form & 74.59 & 29 & .97 & .06 & .03 & .98 \\
\hline
\end{tabular}




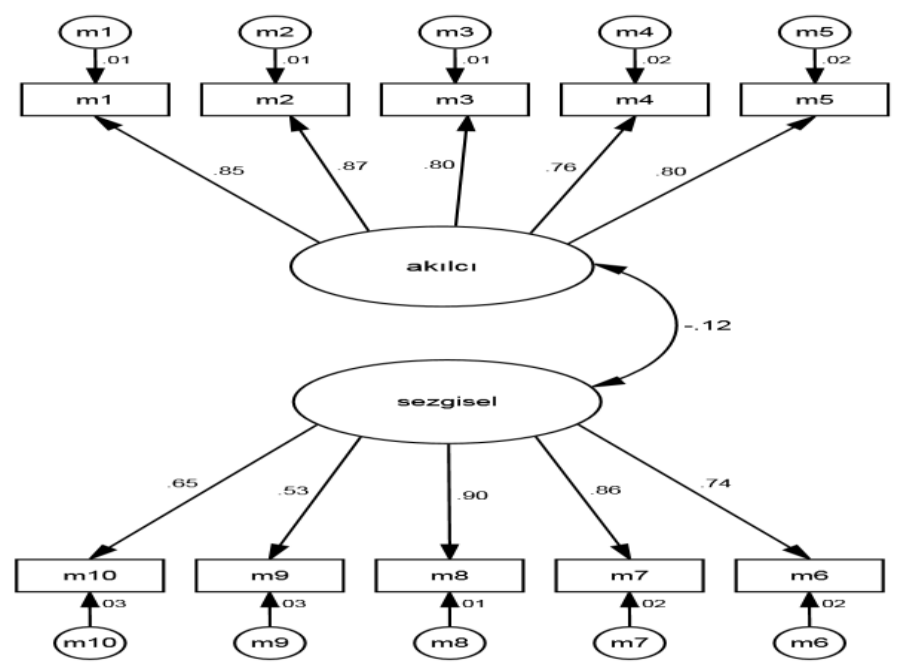

Şekil 1.Akılcı ve Sezgisel Karar Verme Ölçeği'ne ilişkin faktör değerleri

Şekil 1'den de anlaşılacağı gibi ölçek maddelerinin faktör yükleri 53 ile .90 değerleri arasında değişim göstermektedir. Modelin uyum indeksleri incelendiğinde ölçeğin iki boyutlu modelinin uyum değerlerinin kabul edilebilir düzeyde olduğu saptanmıştır $\left(x^{2}=74.59, \mathrm{df}=29, \mathrm{p}<.001 ; \mathrm{CFI}=.98\right.$; TLI=.97; SRMR=.06; RMSEA=.06).

\section{Ölçüt Bağlantı Geçerlik}

Akılcı ve Sezgisel Karar Verme Ölçeği'nin ölçüt bağlantı geçerliliği için Taşdelen (2001) tarafından Türkçeye uyarlanan karar verme stilleri ölçeği ile arasındaki ilişki incelenmiştir. Bu iki ölçeğin alt boyutları arasındaki ilişkiyi gösteren korelasyon değerleri ve tanımlayıcı istatistiklerini belirten bulgular Tablo 5'te gösterilmektedir.

Tablo 5. Akılcı ve Sezgisel Karar Verme ile Karar verme stilleri arasındaki ilişkiye yönelik korelasyon değerleri

\begin{tabular}{lllll}
\hline Değişkenler & $\mathbf{1}$ & $\mathbf{2}$ & $\mathbf{3}$ & $\mathbf{4}$ \\
\hline 1. Akılcı karar verme & $\mathbf{1}$ & .08 & $.78^{* *}$ & .04 \\
\hline 2. Sezgisel karar verme & & $\mathbf{1}$ & -.02 & $.59^{* *}$ \\
\hline 3.Rasyonel karar verme & & $\mathbf{1}$ & .06 \\
\hline 4. Sezgisel karar verme & & & $\mathbf{1}$ \\
\hline Ortalama ( $\bar{X}$ ) & 18.05 & 15.23 & 18.05 & 16.29 \\
\hline Standart Sapma (SS) & 3.36 & 3.39 & 2.85 & 3.09 \\
\hline
\end{tabular}


Tablo 5'te görüldüğü üzere akılcı ve sezgisel karar verme ölçeğinin alt boyutları olan akılcı karar verme ile karar verme stilleri ölçeğinin alt boyutu rasyonel karar verme puanları arasında (.78) pozitif ilişki bulunmuştur. Yine, akılcı ve sezgisel karar verme ölçeğinin alt boyutu olan sezgisel karar verme ile karar verme stilleri ölçeğinin alt boyutu olan sezgisel karar verme puanları arasında (.59) pozitif ilişki bulunmuştur.

\section{Güvenirlik Çalışması}

Yapılan güvenirlik çalışmasında akılcı ve sezgisel karar verme ölçeğinin geneli için Cronbach Alpha değeri. 80 olarak saptanmıştır. Diğer yandan ölçeğin alt boyutları akılcı karar verme için. 90 ve sezgisel karar verme için ise .85 olarak bulunmuştur. Akılcı ve sezgisel karar verme ölçeğinin testtekrar test çalışması 2 hafta aralıklı bir süre ile 58 katılıcımcıya uygulanarak bulunmuştur. Buna göre göre ölçeğin toplam test-tekrar test korelasyon değeri .86 olarak bulunmuştur. Akılcı karar verme için .84 sezgisel karar verme için ise .82 olarak bulunmuştur.

\section{Tartışma}

Bu araştırma Hamilton ve diğ. (2018) tarafından geliştirilen "Akılcı ve Sezgisel Karar Verme Ölçeği"ni Türkçeye uyarlamak amaciyla gerçekleştirilmiştir. Bu amaçla öncelikle ölçeğin orijinal formu İngilizce ve Türkçe dillerine hakim altı kişi tarafından Türkçeye çevrilmiştir. Daha sonra 5 bağımsız uzman ölçeği İngilizceye geri çeviri yapmıştır. Devamında Türkçe formun uygulamaya hazır hale geldiği görülmüştür.

Akılcı ve sezgisel karar verme ölçeği için yapılan yapı geçerlik sonuçları ölçeğin geçerli bir ölçme aracı olduğunu göstermektedir. Yapılan doğrulayıC1 faktör analizi ölçeğin orijinal formunda yer alan akılcı ve sezgisel olarak iki alt boyutunun kabul edilebilir değerler arasında uyum sağladığını göstermektedir. DFA sonucunda elde edilen korelasyon katsayıları .53 ile. 90 arasında değişmektedir. Korelasyon katsayıları .30 ve üzerinde değer alan maddelerin temsil gücünün yeterli olduğu belirtilmektedir (Büyüköztürk, 2018). Bu açıdan ölçeğin tüm maddelerinin korelasyon katsayı değerlerinin yeterli olduğunu söyleyebiliriz. Bu nedenle uyarlama çalışması sonucu herhangi bir madde çıkarılmamıştır. Elde edilen bulgular akılcı ve sezgisel ka- 
rar verme ölçeğinin Türk kültüründe geçerliğe sahip ölçek olduğunu sunmaktadır.

Akılcı ve sezgisel karar verme ölçeğinin ölçüt geçerliği çalışması için benzer bir ölçek olarak düşünülen karar verme stilleri ölçeği ile arasındaki ilişkiye bakılmıştır. Akılcı ve sezgisel karar verme ölçeğinin alt boyutları olan akılcı karar verme ve sezgisel karar verme ile karar verme stilleri ölçeğinin alt boyutları olan rasyonel karar verme ve sezgisel karar verme arasında pozitif yönlü anlamlı ilişkiler saptanmıştır. Bu durum ölçeğin ölçüt geçerliğini sağladığı şeklinde yorumlanabilir.

Ölçeğin güvenirlik çalışmalarında tümü için Cronbach Alpha iç tutarlılık güvenirlik katsayı değeri .80 olarak hesaplanmıştır. Alt boyutlara baktığ1mızda ise akılcı karar verme için. 90 ve sezgisel karar verme için ise .85 olarak saptanmıştır. Cronbach alpha iç tutarlık katsayısı değerinin Özgüven (1994) tarafından .70 ve üzerinde olması gerektiği belirtilmektedir. Elde edinilen bulgular ölçeğin güvenilir olduğunu sunmaktadır. Ayrıca akılcı ve sezgisel karar verme ölçeğinin test-tekrar test güvenirlik çalışması sonucunda bulunan .86 korelasyon değeri zamana bağlı olarak ölçeğin tutarlı ölçme bulguları verdiğini belirtmektedir.

Yapılan araştırmada 2 haftalık zaman aralığında test-tekrar test güvenilirliği, öğrencilerin akıla ve sezgisel karar tarzlarının çok fazla değişmediğini göstermektedir. Gelecek araştırmalarda daha uzun sürelerde bireylerde karar stillerinin değişip değişmediğini ortaya çıkarmak için ilgili araştırmalar yapılabilir.

Çalışmanın en önemli sınırlılıklarından birini örneklemin tamamen üniversite öğrencilerinden oluşmasıdır. Üniversiteler bilindiği üzere genel olarak rasyonel karar vermeyi öğrencilere öğretmeyi amaçlar. Dolayısıyla bu durumda örneklemdeki kişiler karar verme süreçlerini daha rasyonel bir yaklaşımla ele almış olabilirler. Bu durum da akılcı karar verme becerileri yüksek bireylerin daha güçlü temsiline yol açabilir. Araştırmamızın diğer bir sinırlılığ1 tüm verilerin öğrencilerin özbildirimde bulunarak anketleri doldurması oluşturmaktadır. Bu durumda katılımcılar sosyal cazibeden etkilenerek kendileri için en uygun olması gereken cevabı vermiş olabilirler. Bu nedenle gözlemsel ve çeşitli görüşme tekniklerine dayalı veri toplamak da karar verme konusu ile ilgili detaylı bilgi toplanması açısından faydalı olabilir. Yine karar verme stilleri ile ilgili olarak boylamsal bir çalışma yapilarak yıllar içerisinde bireylerin karar verme stillerinin değişip değişmediği 
ile ilgili araştırma yapılabilir. Ayrıca yapılan güncel çalışmalarda lise öğrencilerinde karar vermenin başarı yönelimlerinin önemli bir yordayıcısı olduğu (Ümmet, İme, Çağlar ve Aky1l, 2020) ifade edilmekte olup, üniversite öğrencilerinde de karar verme stillerine göre başarı yönelimlerinin yordayıcı olup olmadığına yönelik çalışmalar da yapılabilir.

Sonuç olarak yapılan yapılan çalışma akılcı ve sezgisel karar verme ölçeğinin Türkiye'deki üniversite öğrencilerinde psikometrik olarak kabul edilebilir uyum değerleri sergilediğini, iç tutarlılık, test-tekrar test katsayı değerinin yüksek olduğunu ve ölçüt bağlantı geçerliliğinin de karşılandığını sunmaktadır. Bu bağlamd ileriki zamanlarda üniversite öğrencileriyle yapılabilecek çalışmalarda akılcı ve sezgisel karar verme ölçeği kullanılabilir.

\section{Ölçeğin Puanlanması ve Yorumlanması}

Akılcı ve sezgisel karar verme ölçeği toplam 10 madde ve iki alt boyuttan oluşmaktadır. İlk beş madde akılcı, diğer beş madde ise sezgisel karar vermeyi belirlemeye yönelik maddelerdir. Ölçek kesinlikle katılmıyorum ve kesinlikle katıllyorum seçenekleri arasında değişen 5'li likert yapıdadır. Ölçeğin 10 maddesinden toplam puan alınamaz ancak alt boyutlardan toplam puan alınabilir. Her bir alt boyut için minimum beş maksimum yirmi beş puan alına bilinir. Alınan yüksek puanlar bireyin akılcı veya sezgisel karar verme stilinin yüksek olduğunu gösterir. 


\title{
EXTENDED ABSTRACT
}

\section{Adaptation of Rational and Intuitive Decision Making Styles Scale to Turkish}

\author{
Yakup Ime - Makbule Kalı Soyer - Muhammet Şerif Keskinoğlu \\ Ministry of National Education, Marmara University,
}

In reality, decision making styles form the backbone of effective decision making (Rowe and Boulgarides, 1992). In this context, decision-making styles have attracted an increasing amount of interest from many researchers around the world and Turkey (Taşdelen, 2001; Wood and Highhouse, 2014). Notwithstanding this growing interest, scales enabling psychometric analysis of decision-making styles are criticized by many researchers both due to insufficient theoretical background and inadequate structural validity (Spicer and Sadler-Smith, 2005; Mohammed and Schwall, 2009). With reference to these criticism, Hamilton, Shih and Mohammed (2016) created a new measurement tool on decision-making styles that is more systematic. This measurement tool treats decision-making styles as rational and intuitive. The rational decision-making style is a thorough investigation, a systematic evaluation of all options and possible alternatives. However, the intuitive decision-making style is the use of a rapid decision-making process based primarily on intuitions and emotions (Scott and Bruce, 1995). But then in Turkey, when the literature is evaluated, there are various scales for measuring decision-making styles (Taşdelen, 2001; Çolakkadioğlu, 2012). Nevertheless, it is thought that the introduction of an up-to-date scale to the literature will contribute to scientific studies in this field in terms of enriching the measurement tools in the field of decision-making styles. Hence, the research aims to adapt the rational and intuitive decision-making scale to Turkish.

The purpose of this research is to adapt the rational and intuitive decision styles scale into Turkish and to evaluate its reliability and validity in Turkish culture. For this purpose, survey method was used. Survey method is a systematic scientific method used to gather information from a sample (Lavrakas, 2008). 
740 university students participated in this study. For the language validity, 46 university students ( $56.5 \%$ women, $43.5 \%$ men, age $=21.08$, Ss) participated. A total of 419 university students $(47.8 \%$ female, 52.2\% Male, $=21.21$ age $S s=3.99$ ) participated in the confirmatory factor analysis and reliability study. A total of 217 university students, 99 women and 118 men, participated in the research for the criterion validity study $(45.6 \%$ women, $54.4 \%$ men, $=$ 20.94 age $S s=3.74)$. For the test-retest reliability study, a total of 58 university students participated $(60.3 \%$ girls, $39.7 \%$ men, $=21.10$ age $S s=1.20)$.

Rational and Intuitive Decision-Making Scale: The scale is developed by Hamilton and others (2018), a two-dimensional structure consists of ten items and that can be answered on 5-point likert style. The fit indices of the model represented by two dimensions were found to be acceptable $(x 2 / \mathrm{DF}=2.57, \mathrm{CFI}=.98, \mathrm{TLI}=.97, \mathrm{SRMR}=.06, \mathrm{RMSEA}=.06)$. The criterion validity study found positive significant relationships between the rational and intuitive decision making scale and the sub-scales of the decision-making styles scale. Internal coherence reliability Cronbach Alpha coefficient was calculated as .80 for the overall scale, .90 for rational decision-making, and .85 for intuitive decision-making. The test-retest correlation coefficient has been calculated as 86 .

The Decision-Making Styles Scale: Decision-making scale was developed by Scott and Bruce (1995) The scale consists of five sub-dimensions and 25 items. The adaptation of the scale into Turkish was done by Taşdelen (2001). The scale consists of five sub-dimensions and 25 items. In the reliability study, the Cronbach alpha coefficient for the sub-dimensions of the scale varies between .76 and .79 and for all of them it is .74 (Taşdelen, 2001).

During the analysis process of the data, language , criterion validity, internal coherence reliability, test-retest and CFA methods were used. Within the scope of the criterion validity of the decision-making styles scale, the relationship between the decision-making styles scale was examined. CFA was performed to test the two-factor structure of the rational and intuitive decisionmaking styles.

According to CFA results the factor loads of the scale ranges between .53 and .90 . When the model's goodness of fit indices are analyzed, it is seen that the three-dimensional model of the scale gives acceptable fit $\left(x^{2}=74.59, \mathrm{df}=29\right.$, $\mathrm{p}<.001 ; \mathrm{TLI}=.97$; RMSEA=.06; SRMR=.03; CFI=.98). 
There has been found a positive relationship (.78) between rational decision-making, and rational decision-making, which is the sub-dimension of decision-making styles scale. Again, a positive relationship (.59) has been found between intuitive decision making and intuitive decision-making scores.

The correlation coefficient between the English form and the Turkish form score has been found as $\mathrm{r}=.90$ ( $\mathrm{p}<.01)$. For the sub-scales, the correlation coefficient has been found to be $\mathrm{r}=.88$ for rational decision-making sub-scale and $\mathrm{r}=.94$ for intuitive decision-making sub-scale.

Cronbach Alpha internal consistency coefficient for all rational and intuitive decision-making scale in reliability study has been found to be 80 . Also, it was calculated as .90 for rational decision making and .85 for intuitive decision making. As obtained from the analysis results, the test-retest correlation coefficient of the scale was calculated as ".86".

The construct validity results for the rational and intuitive decisionmaking scale shows its validity. Confirmatory factor analysis shows that two sub-dimensions of the scale, which are in the original form of the scale, have been rationally and intuitively confirmed. Correlation values vary between .53 and .90 .

Significant positive relationships were found between rational decision making and intuitive decision making, which are the sub-dimensions of rational and intuitive decision-making scale, and rational decision making and intuitive decision making, which are the sub-dimensions of decision-making scale. Hence, the scale provides criterion validity.

For the reliability of the scale, Cronbach Alpha internal reliability coefficient was found as .80 . For the sub-dimensions, it was calculated to be .90 for rational decision making and .85 for intuitive decision making. Moreover, the .86 correlation coefficient obtained as a result of the test-retest study of the rational and intuitive decision-making scale indicates that it shows sustained results in a period of time. The test-retest reliability in the 2-week timeframe shows that the students' rational and intuitive decision styles do not change so much.

As a result, this study shows that rational and intuitive decision-making scale shows psychometrically good fit values for university students in Turkey. The internal consistency, test-retest coefficient is high and that it also 
provides criterion validity. Therefore, rational and intuitive decision-making scale can be used in future studies with university students in our Turkey.

\section{Kaynakça / References}

Baiocco, R., Laghi,F. ve D'Alessio,M. (2009). Decision-making style among adolescents: Relationship with sensation seeking and locus of control. Journal of Adolescence, 32,963-976

Büyüköztürk, Ş. (2018). Handbook of data analysis for the Social Sciences. Statistical research pattern SPSS applications and interpretation (24 ${ }^{\text {th }}$ Edition). Ankara: Pegem Academy

Çolakkadıoğlu, O.(2012). The reliability and validity study of adolescent decisionmaking questionnaire for the high school students. Journal of The Institute Of Social Sciences Of Mustafa Kemal University, 9(19), 387-403.

Driver, M. J., Brousseau, K. E. ve Hunsaker, P. L. (1990). The dynamic decision maker. New York, NY: Harper \& Row

Driver, M. J., Svensson, K., Amato, R. P. ve Pate, L. E. (1996). A human informationprocessing approach to strategic change: Altering managerial decision styles. International Studies of Management and Organization, 26, 41-58.

Hamilton,K Shih,S.I. ve Mohammed,S. (2016). The development and validation of the rational and intuitive decision styles scale. Journal of Personality Assessment, 98(5), 523-535.

Hunt, R. G., Krzystofiak, F. J., Meindl, J. R. ve Yousry, A. M. (1989). Cognitive style and decision making. Organizational Behavior and Human Decision Processes, 44, 436-453.

Kinicki, A. ve Williams, B. (2013). Management: A practical introduction (6th edition). New York: McGraw-Hill.

Kline, R.B. (2005).Principles and practice of structural equation modeling (Second Edition). NY: Guilford Publications.

Lavrakas, P.J. (2008). Introduction. P.J. Lavrakas (Ed.), Encyclopedia of Survey Research Methods içinde (s.35-41). California: Sage.

Leykin,Y. ve DeRubeis, R. J.(2010). Decision-making styles and depressive symptomatology: Development of the Decision Styles Questionnaire. Judgment and Decision Making, 5(7), 506-515.

Maruyama, G.M. (1998). Basics of structural equation modeling (First Edition).CA: Sage Publications.

Miller, D. C. ve Byrnes, J. P. (2001). Adolescents' decision making in social situations. A self-regulation perspective. Applied Developmental Psychology, 22,237-256. 
Nutt, P. C. (1990). Strategic decisions made by top executives and middle managers with data and process dominant style. Journal of Management Studies, 27, 173194

Özgüven, İ. E. (1994). Psychological tests. Ankara: Yeni Dogus Printing House.

Phillips, W. J., Fletcher, J. M., Marks, A. D. G. ve Hine, D. W. (2016). Thinking styles and decision making: A meta-analysis. Psychological Bulletin, 142(3), 260-290

Rowe, A. J. ve Mason, R. O. (1987). Managing with style: A guide to understanding, assessing, and improving decision making. San Francisco, CA: Jossey-Bass

Rowe, A. J. ve Boulgarides, J. D. (1992). The decision maker. A. J. Rowe ve J. D. Boulgarides (Ed.), Managerial decision making: A guide to successful business decisions (s. 21-43). New York:Macmillan.

Rowe, A. J. ve Davis, S. A. (1996). Intelligent information systems: Meeting the challenge of the knowledge era. Westport: Quorum Books.

Scott,S.G. ve Bruce, R. A. (1995). Decision-making style: The development and assessment of a new measure. Educational and Psychological Measurement, 55, 818831.

Sireci,S.G., Patsula,L. ve Hambleton,R.K.(2005). Statistical methods for identifying flaws in the test adaptation process. R.K. Hambleton, P. F. Merenda ve C. D. Spielberger (Eds.)Adapting educational and psychological tests for cross-cultural assessment içinde (s.93-116). London: Lawrence Erlbaum Associates.

Spicer, D. P. ve Sadler-Smith, E. (2005). An examination of the general decisionmaking style questionnaire in two UK samples. Journal of Managerial Psychology, 20, 137-149.

Şeker,H. ve Gençdoğan, B.(2014).Psikolojide ve eğitimde ölçme aracı geliştirme (2. Basım). Ankara: Nobel Yayınları.

Tabachnick B.G. ve Fidel, L.S. (2001).Using multivariate statistics (4th Edition).MA: Allyn and Bacon.

Taşdelen,A.(2001). Teacher candidates' decision-making styles based on some psychosocial variables. Pamukkale University Faculty of Education,10(10),40-52.

Ümmet,D.,İme,Y.,Çağlar,A. ve Akyıl, Y.(2020).Lise öğrencilerinde karar verme: olumsuz değerlendirilme korkusu ve başarı yönelimlerine gore bir değerlendirme.Humanistic Perspective,2(2),68-80.

Wood, N. L. ve Highhouse, S. (2014). Do self-reported decision styles relate with others' impressions of decision quality? Personality and Individual Differences, 70, 224-228. 


\section{Kaynakça Bilgisi / Citation Information}

İme, Y., Kalı Soyer, M. ve Keskinoğlu, Ş. M.(2020).Akılcı ve sezgisel karar verme stilleri ölçeğinin Türkçeye uyarlanması. OPUSUluslararası Toplum Araştırmaları Dergisi, 16(Eğitim ve Toplum Özel Sayıs1), 5995-6013.DOI: 10.26466/opus.720827 